\title{
¿On the Observed Inverse Relationship between Rainfall Amount and Dissolved Mineral Content
}

\author{
JOHN E. STOUT \\ USDA-Agricultural Research Service, Lubbock, Texas
}

(Manuscript received 17 September 2018, in final form 25 February 2019)

\begin{abstract}
Rainfall samples collected on the high plains of West Texas exhibit a high degree of variability with respect to the concentration of dissolved solids. That such variations should occur is to be expected, but there remains some uncertainty regarding factors that influence the ionic composition of individual samples. Measurements often show a distinct decrease in concentration with increasing precipitation amount. The reason for this inverse relationship is not intuitively obvious; however, it can be explained from a theoretical perspective. A theory was proposed that describes the concentration of dissolved solids in a collected rainfall sample. The theoretical basis of the derived equation rests upon fundamental principles of conservation of fluid volume and conservation of mass. This equation, which provides valuable insight into the process, suggests that if the rain sampling tube is absolutely clean at the start of a rain event, then the rainfall sample will not be altered by its collection and, therefore, will provide a true measure of rainfall chemistry. However, if windblown dust or other impurities are allowed to deposit in the rain gauge prior to or during the early stages of a rain event, then the concentration of dissolved solids can be very large for small sample volumes and not at all representative of the true concentration within the rain cloud. Results suggest that impurities in the rain sample can be appreciably diluted by the addition of relatively pure rainwater such that the concentration will asymptotically approach the true concentration as the rainfall sample volume increases.
\end{abstract}

\section{Introduction}

The Llano Estacado of western Texas and eastern New Mexico is a vast tableland that stands in high relief at the southern end of the Great Plains of North America (Cummins 1892; Johnson 1901; Fenneman 1931). This expansive stretch of elevated plains is favorably situated above a significant portion of the Ogallala Aquifer, which has provided groundwater for a productive irrigated agricultural system (Lewis 1990; Opie 2000). The extraction of groundwater, coupled with the lack of any significant recharge, has gradually reduced the remaining volume of stored water in the Ogallala Aquifer (Musick et al. 1990; Postel 1992; Alley 2006). Eventually, many farms on the high plains will be forced to transition from irrigated to rain-fed agriculture.

As the region's economy becomes increasingly dependent on rainfall, knowledge of various aspects of

D Denotes content that is immediately available upon publication as open access.

Corresponding author: John E. Stout, john.stout@ars.usda.gov precipitation, in its many forms, becomes increasingly important. Agricultural producers will need to know more about the quantity of rain, the timing and distribution of rain events, and possible variations of rainfall chemistry.

The focus of this study was on a specific aspect of rainfall chemistry. The initial goal was to determine if rainwater salinity varies seasonally or if atmospheric conditions such as wind direction or wind speed had any affect on rainwater salinity. A field campaign was initiated to collect samples of rainwater on the Llano Estacado for analysis. Preliminary results suggest that there is a surprisingly weak correlation between rainfall chemistry and atmospheric conditions, such as wind speed or direction. Although the dissolved mineral content of precipitation was observed to vary significantly over time, no obvious seasonal pattern was discernible. Further analysis of rainfall samples did, however, show a significant inverse relationship between the concentration of total dissolved solids and the amount of rainfall collected in the rain gauge. The reason for this inverse correlation was not initially clear. 
A decrease in rainwater salinity with precipitation amount has been noted by several observers (Junge 1958). After collecting numerous bulk rainfall samples in the Mojave Desert, Feth (1967) found that the specific conductance of rain generally follows a "strong inverse correlation" with the volume of the rainfall sample. Similar observations in India and China by Handa (1969), Rastogi and Sarin (2007), and Zhang and Liu (1994) have shown that large rain events typically have a much lower concentration of dissolved mineral content compared to smaller rain events. Similar investigations by Mordy (1953), Woodcock (1952), and Larson and Hettick (1956) found an inverse relationship between solute concentration and rainfall intensity. This inverse relationship between dissolved mineral concentration and rainfall amount has never been fully explained.

As will be demonstrated, the relationship between dissolved mineral concentration and rainfall amount can be explained from basic principles.

\section{Theory}

Consider a cylindrical rain gauge of radius $r$. As it begins to rain, the volume of rainwater in the cylinder increases with time as indicated by the depth of water $h$ in the cylinder. At any time $t$ during a rain event the volume of rain $V(t)$ within the cylinder is equal to

$$
V(t)=\pi r^{2} h(t) .
$$

The rate of change of the volume of rainwater within the cylinder is equal to the flow of rainwater $Q$ into the cylinder:

$$
\partial V / \partial t=Q(t)=\pi r^{2} \partial h / \partial t .
$$

At any given moment $t$, the mass of dissolved solids in the rainwater sample $m(t)$ is equal to the concentration $c(t)$ times the volume of the sample $V(t)$ :

$$
m(t)=c(t) V(t)=\pi r^{2} c(t) h(t) .
$$

The time rate of change of the mass of dissolved solids within the cylinder is

$$
d m / d t=d(c V) / d t=c \partial V / \partial t+V \partial c / \partial t .
$$

Combining Eqs. (1), (2), and (4) yields

$$
d m / d t=c \pi r^{2} \partial h / \partial t+\pi r^{2} h \partial c / \partial t .
$$

The time rate of change of the mass of dissolved solids is equal to the volumetric flowrate of rainwater $Q$ into the cylinder times the concentration of dissolved solids in the rainwater $c_{r}$, which may be written as

$$
d m / d t=c_{r} Q(t)=c_{r} \pi r^{2} \partial h / \partial t .
$$

Combining Eqs. (5) and (6) yields

$$
c \partial h / \partial t+h \partial c / \partial t=c_{r} \partial h / \partial t .
$$

Note that Eq. (7), which governs the concentration of dissolved solids within rainfall samples, is independent of the diameter of the rain gauge. Rearranging Eq. (7) yields

$$
\frac{\partial c}{c_{r}-c}=\frac{\partial h}{h} .
$$

By integrating both sides, the solution of this equation is obtained in final form:

$$
\frac{c}{c_{o}}=\frac{c_{r}}{c_{o}}+\left(1-\frac{c_{r}}{c_{o}}\right) \frac{h_{o}}{h}
$$

where the reference concentration $c_{o}$ and the reference depth of water $h_{o}$ in the sampling tube are linked such that the concentration $c$ is equal to $c_{o}$ when the amount of rain $h$ is equal to the reference amount $h_{o}$.

Note that the concentration of dissolved solids of the rainfall sample becomes very large as $h \rightarrow 0$ and is undefined if $h=0$. At the opposite extreme, the concentration of the rain sample approaches the true concentration of the rain $\left(c \rightarrow c_{r}\right)$ as the amount of rain $h$ increases $(h \rightarrow \infty)$.

For the sake of theoretical discussion suppose we make the unrealistic assumption that rainwater entering the cylinder is pure water that contains no dissolved solids. In this case, $c_{r}=0$ and Eq. (9) reduces to

$$
\frac{c}{c_{o}}=\frac{h_{o}}{h},
$$

which suggests that the concentration of rainwater varies inversely with the amount of rainwater collected or $c \sim h^{-1}$. Our data show that this is not the case and therefore proves that, although rainwater typically has a low concentration of dissolved solids, the concentration is not zero.

It is also interesting to note that when $c_{o}=c_{r}$, Eq. (9) reduces to

$$
c=c_{r} .
$$

In this ideal case where the rain gauge is initially absolutely clean, the chemistry of the collected rainwater is not altered and the concentration of dissolved solids remains constant and equal to the true concentration of the raindrops. In this case, the concentration of dissolved solids becomes independent of the amount of 


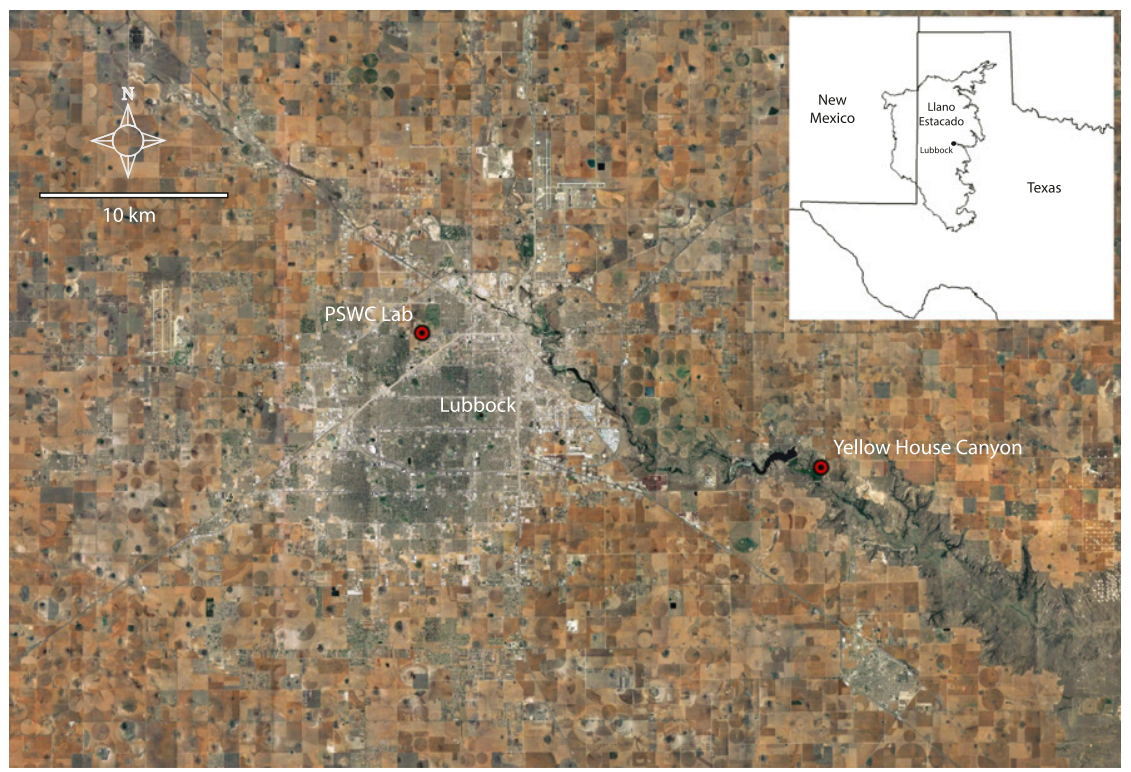

FIG. 1. Map showing the location of the PSWC Laboratory and Yellow House Canyon rainfall sampling sites used during this study. Both sites are located at or near Lubbock on the high plains of the Llano Estacado of West Texas.

rain $h$ collected in the rain gauge. This suggests that for the concentration of dissolved solids to change while rain is collected, there must be an initial source of impurities entering the sampling tube before or during the initial stages of the rain event that is diluted over time by relatively clean rainwater.

\section{Field study}

Over the past five years, rainfall samples were collected at two locations on the high plains of the Llano Estacado (Fig. 1). One sampling site was located on the roof of the USDA-ARS Plant Stress and Water Conservation (PSWC) Laboratory in Lubbock, Texas $\left(33.5935^{\circ} \mathrm{N}, 101.8977^{\circ} \mathrm{W}\right)$, and another sampling site was located near the rim of Yellow House Canyon near the residential community of Ransom Canyon, located $22 \mathrm{~km}$ to the east of Lubbock $\left(33.5312^{\circ} \mathrm{N}, 101.6763^{\circ} \mathrm{W}\right)$.

Each sampling site was located near an existing meteorological tower that collected basic information such as wind speed and direction, temperature, relative humidity and atmospheric pressure. Each meteorological tower also included a tipping-bucket rain gauge so that the timing of the rain event could be determined more precisely. No attempt was made to save the rain that passed through the tipping bucket; instead, standard manual rain gauges were used to collect rainfall samples for post-storm analyses. Each manual rain gauge consisted of a $102 \mathrm{~mm}$ diameter plastic cone perched above a $32 \mathrm{~mm}$ diameter sampling tube. Whenever possible, a clean sampling tube was deployed as close to the start of the anticipated rain event as possible.

The rain gauge was allowed to collect a sample during what was considered to be a complete rain event. Ideally, a rain event is defined as the period between the start of rainfall and the point at which the rain event has come to a clear stopping point. In reality, the start and end points of any rain event are not always well defined or predictable. Often a rain event will begin with a few intermittent sprinkles interspersed with rain-free periods. After a few false starts, a more significant downpour may follow. During the main portion of the rain event, it is not unusual for rain intensity to be highly variable with occasional starts and stops throughout the event. The sampling tube was not removed after any of these brief intermittent pauses; rather, it was removed only when rainfall was judged to have stopped completely and in most cases when skies cleared.

When rain occurred at night, a fresh tube was set out before the rain event and then retrieved the next morning. If a rain event lasted for more than one day, then a sample was retrieved during any significant pause the following day.

When attempting to collect rainfall samples for chemical analysis, one would prefer to start with a clean rain gauge. However, such a simple initial condition is rarely achieved. The unpredictable nature of rainfall made it impossible to ensure that the sampling tube was exposed to the environment only during periods of active rainfall. In many cases, a fresh sampling tube was 
deployed when rain was fast approaching only to find that the anticipated rain dissipated or was delayed by many hours. Such is the nature of rainfall on the Llano Estacado.

There are many potential sources of contamination, some of which can be avoided while others are unavoidable (Eriksson 1952). On the high plains of the Llano Estacado, a region with a long history of dust storms, pulses of blowing dust and sand often precede rain events as wind gusts associated with falling rain or down drafts caused by thunderstorm outflows may detach a considerable quantity of dust and a small portion may deposit in the rain gauge prior to the inception of rainfall. Dust may also be mixed together with rain and fall as "mud rain." Thus, windblown dust, which may include clay, various salts, and calcium carbonate, may provide an occasional source of dissolved solids in rainfall samples (Desboeufs et al. 2010).

Other sources of foreign matter may include smoke from distant wildfires, vehicle exhaust, and other combustion products. Bird droppings, insects, windborne seeds, pollen, and other plant materials can also fall into rain gauges prior to or during a rain event. Ultimately, any foreign matter can influence the ionic composition of a rainfall sample.

For each rainfall sample, the time of collection was noted, the amount of rainfall was recorded, and the sample was placed in a small sterile glass bottle and allowed to come to room temperature (around $23^{\circ} \mathrm{C}$ ) before the electrical conductance was measured. We used a Hach model MP-6 conductivity sensor that was calibrated with a conductivity standard solution of $84 \mu \mathrm{S} \mathrm{cm}^{-1}$.

Although it was possible to measure rainfall to as low as $0.1 \mathrm{~mm}$ with our rain gauge, such a small sample volume was not sufficient for chemical analysis. To obtain a measurement of conductance required a sample volume of at least $4 \mathrm{~mL}$, which for our standard rain gauge is equivalent to a rainfall of around $0.5 \mathrm{~mm}$. Thus, any sample collected during an event that yielded less than $0.5 \mathrm{~mm}$ of rain could not be used in this analysis.

\section{Results}

Rainfall samples were collected at both sites from June 2012 to September 2017. A total of 201 samples were collected at the PSWC Laboratory and 222 samples were collected at Yellow House Canyon (Table 1).

Throughout the 5-yr sampling period one can observe seasonal variations of rainfall activity. It is well known that rainfall on the Llano Estacado tends to peak in the late spring and early summer (Bomar 1983), so it is not
TABLE 1. Seasonal distribution of rainfall samples collected from June 2012 through September 2017.

\begin{tabular}{lcc}
\hline \hline \multirow{2}{*}{ Season } & \multicolumn{2}{c}{ Number of samples } \\
\cline { 2 - 3 } & PSWC Laboratory & Yellow House Canyon \\
\hline Winter & 26 & 25 \\
Spring & 71 & 81 \\
Summer & 75 & 84 \\
Fall & 29 & 32 \\
Total & 201 & 222 \\
\hline
\end{tabular}

surprising that the majority of rainfall samples were obtained during the spring and summer months. At the PSWC Laboratory, 146 of the 201 samples (73\%) were collected during the spring and summer. Similarly, 165 out 222 samples $(74 \%)$ were collected during the spring and summer at Yellow House Canyon. At both locations, the lowest number of precipitation events occurred during the winter season, accounting for only $13 \%$ and $11 \%$ at the PSWC Laboratory and Yellow House Canyon, respectively.

Data collected at both sites provide information necessary to test whether the amount of rain has a significant effect on the concentration of dissolved solids as suggested by Eq. (9). Here electrical conductance is used as a surrogate for the concentration of total dissolved solids.

The final dataset used in this study consists of a long list of data pairs of rainfall amount and measured electrical conductance for each rain event. A plot of measured electrical conductance as a function of rainfall amount is shown in Fig. 2. The black line is Eq. (9) with $h_{o}=1.0 \mathrm{~mm}, c_{o}=100 \mu \mathrm{S} \mathrm{cm}^{-1}$, and $c_{r}=6 \mu \mathrm{S} \mathrm{cm}^{-1}$. The results suggest that Eq. (9) follows the basic trend of the data quite well. These data confirm that there is a significant inverse relationship between conductance and the amount of rainfall collected in the rain gauge. In other words, low rainfall sample volumes are often associated with high conductance values and large rainfall samples tend to have very low concentrations of dissolved solids.

The large amount of scatter is not surprising since the concentration of dissolved solids for any given rain event can be highly variable. Thus, a choice of a single set of parameters for Eq. (9) is not sufficient to describe all rain events. Nevertheless, the results demonstrate that Eq. (9) follows the overall trend of the data points.

The largest amount of scatter occurs at the low end of the curve where rainfall amounts are less than $1 \mathrm{~mm}$. At this low range, measured conductance values can vary from a high of $211 \mu \mathrm{S} \mathrm{cm}^{-1}$ to a low of $12.8 \mu \mathrm{S} \mathrm{cm}^{-1}$. This suggests that at low sample volumes, the concentration of dissolved solids is highly sensitive to any initial 


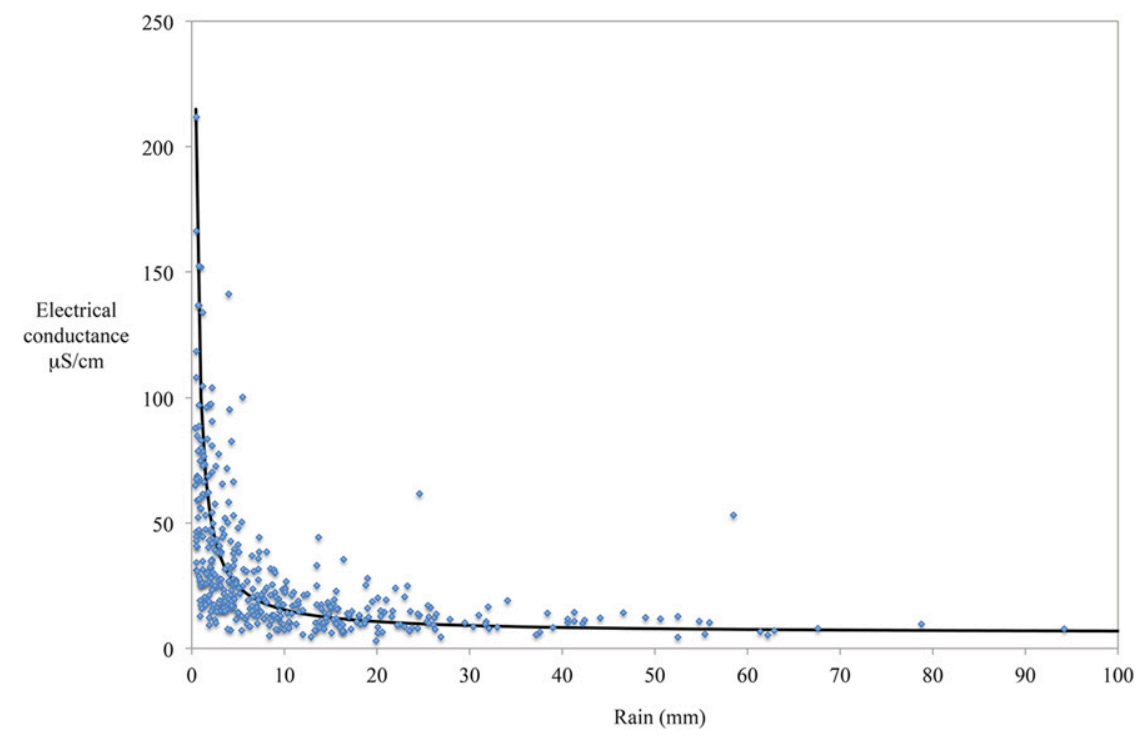

FIG. 2. Plot of measured conductance as a function of rainfall amount for rain samples collected at both the PSWC Laboratory and Yellow House Canyon. The black line is Eq. (9) with $h_{o}=1.0 \mathrm{~mm}, c_{o}=100 \mu \mathrm{S} \mathrm{cm}^{-1}$, and $c_{r}=6 \mu \mathrm{S} \mathrm{cm}^{-1}$.

impurities in the sampling tube that may have been generated by pulses of blowing dust prior to the inception of rainfall.

Figure 2 also shows a few significant outliers situated well outside of the main cluster of plotted points. For example, on 5 June 2013 the concentration was $53.2 \mu \mathrm{S} \mathrm{cm}^{-1}$ for a large rainfall amount of $58.5 \mathrm{~mm}$. A photograph of the sampling tube following this rain event (Fig. 3) shows a considerable amount of windblown dust deposited in the lower half of the sampling tube and a coating of mud was observed on vehicles and glass windows following this rain event. Thus, there is clear evidence that this rain event was associated with an initial dust pulse and mud rain. Other points that are clear outliers also appear to be associated with aeolian dust deposition in the rain gauge prior to the collection of rain.

\section{Conclusions}

Rainfall samples collected on the Llano Estacado exhibit a high degree of variability with regard to the concentration of dissolved mineral content from one rain event to the next. This observed variability has never been fully explained and there remains some uncertainty regarding factors that influence the mineral composition of individual rainfall samples.

Measurements of the concentration of dissolved solids in rainfall samples have shown a distinct decrease in concentration with increasing precipitation amount (Fig. 2). The reason for this inverse correlation between the concentration of dissolved solids and rainfall amount is not intuitively obvious. Here I have attempted to explain this relationship from a theoretical perspective.

An equation was derived that describes the concentration of dissolved solids in a collected rainfall sample [Eq. (9)]. The theoretical basis of the derived equation rests upon fundamental principles of conservation of fluid volume and conservation of mass. This equation, which provides valuable insight into the process, suggests that if the rain sampling tube is absolutely clean at
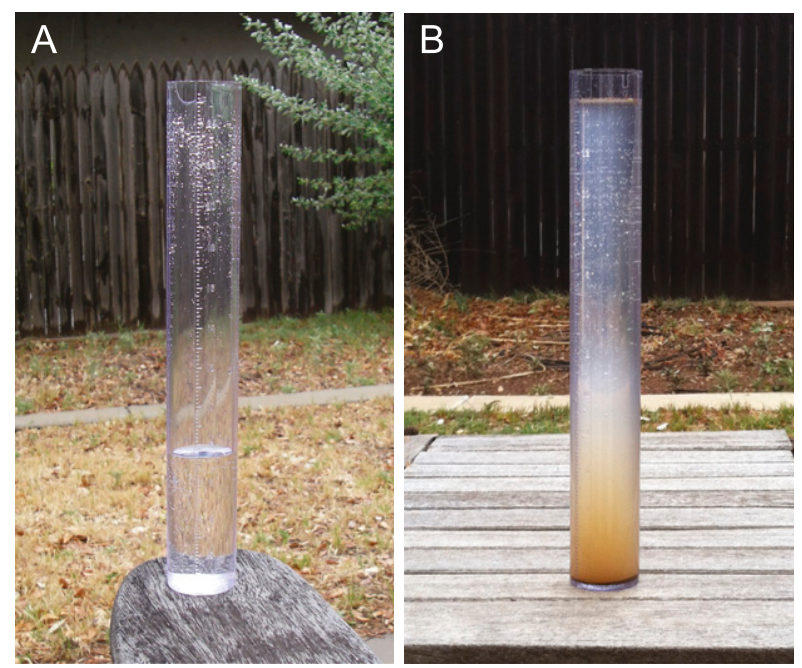

FIG. 3. Photographs showing two rainfall samples collected during this study: (a) a relatively clear sample obtained on 15 May 2016 and (b) a rainfall sample associated with a mud rain obtained on 5 June 2013. 
the start of the rain event, then the rainfall sample will not be altered during its collection and, therefore, will provide a true measure of rainfall chemistry. However, if windblown dust or other impurities are deposited in the rain gauge prior to or during the early stages of a rain event then the concentration of dissolved solids can be very large for small sample volumes and not at all representative of the true concentration within the rain cloud. The theory proposed here also suggests that impurities in the rain sample can be appreciably diluted by the addition of relatively pure rainwater such that the concentration will asymptotically approach the true concentration as the rainfall sample volume increases.

Acknowledgments. The author would like to thank Dean Holder for his assistance in collecting rainfall samples and helping to maintain the meteorological tower at the USDA-ARS Plant Stress and Water Conservation Laboratory. The author would also like to thank Dr. Tim Goebel for sharing his considerable knowledge of general chemistry. Mention of trade names or commercial products in this article is solely for the purpose of providing specific information and does not imply recommendation or endorsement by the U.S. Department of Agriculture. USDA is an equal opportunity provider and employer.

\section{REFERENCES}

Alley, W., 2006: Tracking U.S. ground water: Reserves for the future? Environment, 48 (3), 10-25, https://doi.org/10.3200/ ENVT.48.3.10-25.

Bomar, G. W., 1983: Texas Weather. 1st ed., University of Texas Press, $225 \mathrm{pp}$.

Cummins, W. F., 1892: Report on the geography, topography, and geology of the Llano Estacado or Staked Plains with notes on the geology of the country west of the plains. Third Annual Rep., Geological Survey of Texas, 129-223.

Desboeufs, K., E. Journet, J.-L. Rajot, S. Chevaillier, S. Triquet, P. Formenti, and A. Zakou, 2010: Chemistry of rain events in
West Africa: Evidence of dust and biogenic influence in convective systems. Atmos. Chem. Phys., 10, 9283-9293, https:// doi.org/10.5194/acp-10-9283-2010.

Eriksson, E., 1952: Composition of atmospheric precipitation. I. Nitrogen compounds. Tellus, 4, 215-232, https://doi.org/ 10.3402/tellusa.v4i3.8686.

Fenneman, N. M., 1931: Physiography of Western United States. McGraw-Hill, 534 pp.

Feth, J. H., 1967: Chemical characteristics of bulk precipitation in the Mojave Desert region, California. USGS Professional Paper 575-C, 222-227, https://doi.org/10.3133/pp575C.

Handa, B. K., 1969: Chemical composition of monsoon rains over Calcutta. Part II. Tellus, 21, 101-106, https://doi.org/10.1111/ j.2153-3490.1969.tb00422.x.

Johnson, W. D., 1901: The High Plains and their utilization. Twenty-First Annual Report of the United States Geological Survey, 1899-1900, Part IV-Hydrography, USGS Annual Rep. 21, 601-768, https://doi.org/10.3133/ar21_4.

Junge, C., 1958: Atmospheric chemistry. Adv. Geophys., 4, 1-108, https://doi.org/10.1016/S0065-2687(08)60484-7.

Larson, T., and I. Hettick, 1956: Mineral composition of rainwater. Tellus, 8, 191-201, https://doi.org/10.3402/tellusa.v8i2.8965.

Lewis, J., 1990: The Ogallala Aquifer: An underground sea. EPA J., 16 (6), 42-44.

Mordy, W., 1953: A note on the chemical composition of rainwater. Tellus, 5, 470-474, https://doi.org/10.3402/tellusa.v5i4.8696.

Musick, J., F. Pringle, W. Harman, and B. Stewart, 1990: Long-term irrigation trends: Texas High Plains. Appl. Eng. Agric., 6, 717724, https://doi.org/10.13031/2013.26454.

Opie, J., 2000: Ogallala: Water for a Dry Land. 2nd ed. University of Nebraska Press, 475 pp.

Postel, S., 1992: The Last Oasis: Facing Water Scarcity. W.W. Norton, $239 \mathrm{pp}$.

Rastogi, N., and M. Sarin, 2007: Chemistry of precipitation events and inter-relationship with ambient aerosols over a semi-arid region in Western India. J. Atmos. Chem., 56, 149-163, https:// doi.org/10.1007/s10874-006-9047-5.

Woodcock, A., 1952: Atmospheric salt particles and raindrops. J. Meteor., 9, 200-212, https://doi.org/10.1175/1520-0469(1952) 009<0200:ASPAR > 2.0.CO;2.

Zhang, J., and M. G. Liu, 1994: Observations on nutrient elements and sulphate in atmospheric wet depositions over the northwest Pacific coastal oceans - Yellow Sea. Mar. Chem., 47, 173-189, https://doi.org/10.1016/0304-4203(94) 90107-4. 